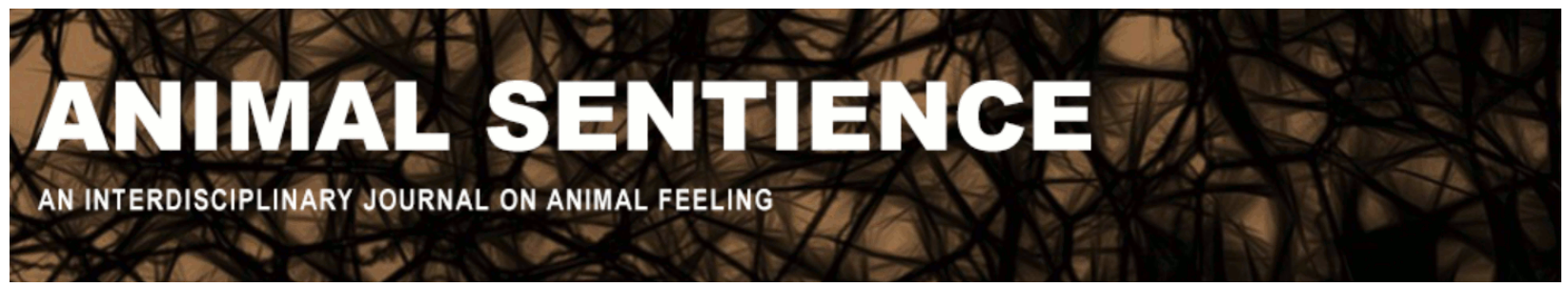

van de Water, Antoinette; Henley, Michelle; Bates, Lucy; and Slotow, Rob (2020) Future of Thailand's captive elephants. Animal Sentience 28(18)

DOI: $10.51291 / 2377-7478.1579$

Date of submission: 2020-05-06

Date of acceptance: 2020-05-15

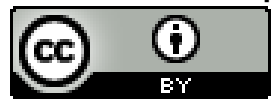




\title{
Future of Thailand's captive elephants
}

Commentary on Baker \& Winkler on Elephant Rewilding

\author{
Antoinette van de Water \\ School of Life Sciences, University of Kwazulu-Natal, South Africa \\ Michelle Henley \\ Applied Behavioural Ecology and Ecosystem Research Unit, University of South Africa \\ Lucy Bates \\ School of Psychology, University of Sussex \\ Rob Slotow \\ School of Life Sciences, University of Kwazulu-Natal, South Africa
}

\begin{abstract}
Removal from natural habitat and commodification as private property compromise elephants' broader societal value. Although we support Baker \& Winkler's (2020) plea for a new community-based rewilding conservation model focused on mahout culture, we recommend an expanded co-management approach to complement and enhance the regional elephant conservation strategy with additional local community stakeholders and the potential to extend across international borders into suitable elephant habitat. Holistic co-management approaches improve human wellbeing and social cohesion, as well as elephant wellbeing, thereby better securing long-term survival of Asian elephants, environmental justice, and overall sustainability.
\end{abstract}

Antoinette van de Water is a PhD researcher, University of Kwazulu-Natal, Director of Bring the Elephant Home, and a Director of the Elephant Specialist Advisory Group of South Africa. Her research focuses on sustainable humanelephant coexistence strategies. Website

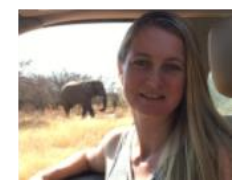

Michelle Henley is a Research Fellow at University of South Africa, Executive Director of Elephants Alive, member of AfESG, and a Director of Elephant Specialist Advisory Group of South Africa. Michelle studies the ecology of elephants, following their movements across international boundaries in southern Africa. Website

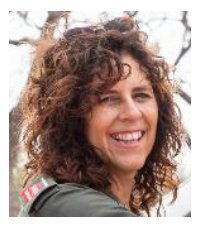

Lucy Bates, Research Fellow, University of Sussex, and a Director of the Elephant Specialist Advisory Group of South Africa, does research on the social behavior and cognitive skills of African elephants and how they affect elephant interactions with humans. Website

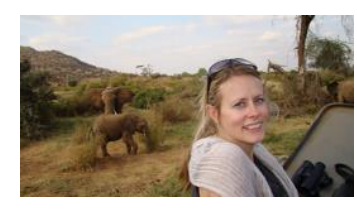

Rob Slotow, Professor, University of Kwazulu-Natal; Honorary Professor, University College London; and Co-Chair of AfESG, studies large mammal conservation, land-use planning for environmental sustainability, and environmental contribution to achieving sustainable development goals. Website 


\section{Introduction}

The novel coronavirus pandemic has currently put over a thousand captive elephants in Thailand out of work, and potentially out of food as well (Paddock \& Suhartono, 2020). The pandemic exposes the vulnerability and unsustainability of wildlife in captivity and illustrates the need for a new and sustainable conservation strategy. Baker \& Winkler (B\&W, 2020) recommend a 3R model (Rescue, Rehabilitate, Rewild) for captive Asian elephants (Elephas maximus) that could benefit both elephants and humans. B\&W propose rewilding captive elephants, facilitated by traditional mahout-guardians who patrol the forest, monitor elephants, reduce human-elephant conflict, and develop ecotourism in their communities.

We recommend taking B\&W's approach further: a large-scale, co-management initiative to connect wild elephant habitat by incorporating "trophic" rewilding principles ("rewilding"1 elephants as a strategy to restore trophic interactions and ecological resilience; Svenning et al., 2016), where elephants will no longer be under direct human control, yet local communities access the benefits of living with elephants. This can promote elephant conservation, ensure sustainability, and enhance socio-economic development.

\section{Conservation outcomes: Integrity of nature}

Fragmentation and loss of habitat play a major role in the decline of both Asian and African (Loxodonta africana) elephants, with increased human-elephant conflict (Hoare, 2015; Robson et al., 2017; Van de Water \& Matteson, 2018; Shaffer et al., 2019). In Thailand, most elephants currently live in small, isolated populations, often below the minimum viable 500 breeding individuals (Sukumar, 1989; Suksawang, 2018). Thailand's 272 protected areas (PAs) cover about $20 \%$ of the country, but elephants inhabit only 69 PAs (Suksawang \& McNeely, 2015; Kitratporn \& Takeuchi, 2020). Only 45\% of available wild land in Thailand has been declared PAs (Leimgruber et al., 2003). Although not all areas will be suitable as elephant habitat, there is wild land available for increasing habitat for elephants, creating and enhancing corridors for connectedness, and improving the long-term viability of Thailand's elephant populations.

The Asian Elephant Specialist Group (AsESG) gives priority to connectivity between elephant populations, and promotes the Managed Elephant Range (MER) approach to achieve such corridors. MERs provide areas managed for elephants, where sustainable and compatible human use is allowed without the need for creating or enlarging PAs (AsESG, 2017). Creating new MERs through targeted captive elephant rewilding can increase the integrity of elephant habitat, provide alternatives for the unsustainable status quo of elephants in captivity, boost elephant numbers in high-deficit elephant areas, and set an example for other elephant range states in innovative elephant conservation (Robson et al., 2017). Reintroduction of elephants into historic ranges has shown positive results in Asia (Baker \& Winkler, 2020; Thitaram et al., 2015) and Africa (Garaï et al., 2004; Millspaugh et al., 2007; Pinter-Wollman, Isbell \& Hart, 2009). Rewilding entire

\footnotetext{
${ }^{1}$ We are aware of the problems with the term "rewilding," as raised by other commentaries (Lee \& Lindsay, 2020); we use it as shorthand for managed and monitored rehabilitation and reintroduction of a species to its "wild" habitat.
} 
social groups, including calves, into suitable habitat helps to create and maintain stable social networks and reduce stress (Jachowski et al., 2013; Thitaram et al., 2015).

\section{Human outcomes: Social cohesion}

In addition to long-term elephant conservation, the main goals of rewilding elephants should align with the Sustainable Development Goals (United Nations, 2014). A holistic approach ensures that mahouts, elephant owners, local communities, and broader society all derive benefits from the conservation of the national elephant population in wild habitat. Mahouts are crucial for a rewilding scheme (Baker \& Winkler, 2020), but the planning and implementation of conservation corridors (MERs) for rewilded captive elephants needs to include other local people as stakeholders to share in the enhancement of wellbeing and livelihoods. The development of skills and alternative livelihoods is critical for achieving overall sustainability (Suksawang, 2018). This includes planting crops that are less attractive to elephants on nearby agricultural land (Gross et al., 2017) and implementing extensive habitat restoration programs (Sitompul et al., 2011) as well as other sustainable human-elephant conflict measures.

Following COVID-19, the tourism landscape will be very competitive. Tourists who visit reserves with rewilded elephants would not only enjoy sightings of elephants in their habitats and "reconnect with nature" (Parker, 2008); they can also experience Thai culture as connected to elephants. The elephant, the national animal of Thailand, can function as a link between the integrity of nature and the wellbeing of the Thai people, reinforcing feelings of pride and ownership, as well as historic cultural, symbolic, and religious values (Ribó, 2017). Broadening $B \& W$ 's focus on rescuing both the elephants and mahouts will engender more participation and buy-in from local communities, conservation agencies, the government, and Thai and global society in general, moving beyond "compassionate conservation" (Bekoff, 2013; Baker \& Winkler, 2020) to self-sustaining "convivial conservation" (Büscher \& Fletcher, 2019).

Acknowledgements: We are grateful to Liesbeth Sluiter for reviewing this commentary prior to submission.

\section{References}

Asian Elephant Specialist Group. (2017). Final Report: Asian Elephant Range States Meeting. IUCN/SSC, Jakarta, Indonesia.

Baker, L., \& Winkler, R. (2020). Asian elephant rescue, rehabilitation and rewilding. Animal Sentience 28(1).

Bekoff, M. (Ed.). (2013). Ignoring nature no more: The case for compassionate conservation. University of Chicago Press.

Büscher, B., \& Fletcher, R. (2019). Towards convivial conservation. Conservation and Society, 17, 283-296.

Garaï, M. E., Slotow, R., Carr, R. D., \& Reilly, B. (2004). Elephant reintroductions to small fenced reserves in South Africa. Pachyderm, 37, 28-36. 
Gross, E. M., Drouet-Hoguet, N., Subedi, N., \& Gross, J. (2017). The potential of medicinal and aromatic plants (MAPs) to reduce crop damages by Asian Elephants (Elephas maximus). Crop Protection, 100, 29-37.

Hoare, R. (2015). Lessons from 20 years of human-elephant conflict mitigation in Africa. Human Dimensions of Wildlife, 20(4), 289-295.

Jachowski, D. S., Slotow, R., \& Millspaugh, J. J. (2013). Delayed physiological acclimatization by African elephants following reintroduction. Animal Conservation, 16(5), 575-583.

Kitratporn, N., \& Takeuchi, W. (2020). Spatiotemporal distribution of human-elephant conflict in eastern Thailand: A model-based assessment using news reports and remotely sensed data. Remote Sensing, 12(1), 90.

Lee, P. C., \& Lindsay, W. K. (2020). A "halfway house" for improving captive welfare. Animal Sentience 28(14).

Leimgruber, P., Gagnon, J. B., Wemmer, C., Kelly, D. S., Songer, M. A., \& Selig, E. R. (2003). Fragmentation of Asia's remaining wildlands: Implications for Asian elephant conservation. Animal Conservation, 6(4), 347-359.

Millspaugh, J. J., Burke, T., Dyk, G. V., Slotow, R., Washburn, B. E., \& Woods, R. J. (2007). Stress response of working African Elephants to transportation and safari adventures. The Journal of Wildlife Management, 71(4), 1257-1260.

Paddock, R. C., \& Suhartono, M. (2020). As tourism plummets in Thailand, elephants are out of work, too. The New York Times.

Parker, K. A. (2008). Translocations: Providing outcomes for wildlife, resource managers, scientists, and the human community. Restoration Ecology, 16(2), 204-209.

Pinter-Wollman, N., Isbell, L. A., \& Hart, L. A. (2009). Assessing translocation outcome: Comparing behavioral and physiological aspects of translocated and resident African elephants (Loxodonta africana). Biological Conservation, 142(5), 1116-1124.

Ribó, I. (2017). Ecocriticism, hermeneutics, and the vanishing elephants of Thailand. In J. C. Ryan, Southeast Asian ecocriticism: Theories, practices, prospects (pp. 37-60). Lexington Books.

Robson, A. S., Trimble, M. J., Purdon, A., Young-Overton, K. D., Pimm, S. L., \& van Aarde, R. J. (2017). Savanna elephant numbers are only a quarter of their expected values. PLOS ONE, 12(4), e0175942.

Sitompul, A. F., Linkie, M., Gunaryadi, D., Purastuti, E., \& Budiman, A. (2011). Ecosystem restoration concessions: A new strategy for conserving elephant habitat in Sumatra? Gajah, 34, 26-31.

Shaffer, L. J., Khadka, K. K., Van Den Hoek, J., \& Naithani, K. J. (2019). Human-elephant conflict: A review of current management strategies and future directions. Frontiers in Ecology and Evolution, 6, 235.

Suksawang, S. (2018). Protected area complexes: A new approach to connectivity in Thailand. Thai Forest Bulletin (Botany), 46, 25-33.

Suksawang, S., \& McNeely, J. A. (2015). Parks for life: Why we love Thailand's national parks. Department of National Parks, Wildlife, and Plant Conservation, and the United Nations Development Programme, Bangkok, Thailand.

Sukumar, R. (1989). The Asian elephant: Ecology and management. Cambridge: Cambridge University Press. 
Thitaram, C., Dejchaisri, S., Somgird, C., Angkawanish, T., Brown, J., Phumphuay, R., Chomdech, S., \& Kangwanpong, D. (2015). Social group formation and genetic relatedness in reintroduced Asian elephants (Elephas maximus) in Thailand. Applied Animal Behaviour Science, 172, 52-57.

United Nations. (2014). Report of the Open Working Group of the General Assembly on Sustainable Development Goals, A/68/970: New York.

Van de Water, A., \& Matteson, K. (2018). Human-elephant conflict in western Thailand: Socioeconomic drivers and potential mitigation strategies. PLOS ONE, 13(6), e0194736. 


\section{Call for Papers}

Special Issue of the Journal of Consciousness Studies

Plant Sentience: Theoretical and Empirical Issues

Guest Editors: Vicente Raja (Rotman Institute of Philosophy, Western University)

Miguel Segundo-Ortin (School of Liberal Arts, University of Wollongong)

In this special issue, we address the issue of plant sentience/consciousness from different disciplines that combine both theoretical and empirical perspectives. Some of the questions to be addressed in the special issue include the following:

- Plants exhibit interesting behaviors; does this entail that they are conscious to some extent?

- What are the requirements for a living organism to be conscious? Do plants meet these requirements?

- What does the possibility of plant sentience/consciousness entail for the study of the evolution of consciousness?

- Is it just a categorical mistake to attribute consciousness to plants?

- Can we talk about different levels or degrees of consciousness?

\section{How to submit?}

\section{Deadline: June 1 $\mathbf{1}^{\text {st }}, \mathbf{2 0 2 0}$}

Please submit your papers (max. 9000 words including footnotes, references, abstract, etc.) to vgalian@uwo.ca with subject "Paper Special Issue JCS".

For more information, including bibliography and more detailed descriptions of the topics and questions to be addressed in the papers submitted to the special issue, please contact the guest editors at vgalian@uwo.ca (Vicente) or mso693@uowmail.edu.au (Miguel). 